\title{
Avaliação da atividade fitotóxica com enfoque alelopático do extrato das cascas de Celtis iguanaea (Jacq.) Sargent Ulmaceae e purificação de dois triterpenos
}

TREVISAN, R.R. ${ }^{1 *}$; LIMA C.P. ${ }^{1}$; MIYAZAKI, C.M.S. ${ }^{1}$; PESCI, F.A. ${ }^{1}$; SILVA, C.B. ${ }^{1}$; HIROTA, B.C.K. ${ }^{1}$; LORDELLO, A.L.L. ${ }^{2}$; MIGUEL, O.G. ${ }^{1}$; MIGUEL, M.D. ${ }^{1}$; ZANIN, S.M.W. ${ }^{1}$

${ }^{1}$ Departamento de Farmácia, Universidade Federal do Paraná, Programa de Pós-Graduação em Ciências Farmacêuticas, CEP: 80210-170, Curitiba-Brasil *robertarafaela@hotmail.com ²Departamento de Química, Universidade Federal do Paraná, CEP: 81531-990, Curitiba-Brasil

\begin{abstract}
RESUMO: A espécie Celtis iguanaea (Jacq.) Sargent é popularmente conhecida como esporão de galo ou grão de galo. As folhas são indicadas pelo uso popular para o tratamento de dores no corpo e no peito, para reumatismo, asma, cólicas, má digestão e como diurético; as raízes são utilizadas para infecções urinárias e as cascas para a febre. O presente trabalho objetivou contribuir para o estudo fitoquímico e atividade fitotóxica com enfoque alelopático das cascas de Celtis iguanaea. O extrato etanólico foi submetido à partição com os solventes hexano, clorofórmio e acetato de etila. As substâncias friedelina e epifriedelinol (triterpenos) foram isoladas da fração hexano e identificadas por meio de métodos espectroscópicos de $\mathrm{RMN}$ de ${ }^{1} \mathrm{H} \mathrm{e}{ }^{13} \mathrm{C}$. O extrato bruto na concentração de $0,1 \mathrm{mg} \mathrm{mL}^{-1}$ causou inibição acentuada do hipocótilo em $34,97 \%$ e estimulou o crescimento da radícula em $29,64 \%$ de plântulas de Lactuca sativa. No ensaio de toxicidade frente à Artemia salina o extrato bruto e frações apresentaram uma $\mathrm{CL}_{50}$ superior a $1000 \mu \mathrm{g} \mathrm{mL}^{-1}$, indicando que o mesmo não possui efeito tóxico.
\end{abstract}

Palavras-chave: aleloquímicos, Celtis iguanaea, epifriedelinol, friedelina, Ulmaceae

ABSTRACT: Evaluation of the phytotoxic activity focused on the allelopathic effect of the extract from the bark of Celtis iguanaea (Jacq.) Sargent Ulmaceae and purification of two terpenes. The species Celtis iguanaea (Jacq.) Sargent is popularly known as "esporão de galo" or "grão de galo". Its leaves are recommended by the popular use for the treatment of body and chest aches, as well as for rheumatism, asthma, cramps, indigestion and as diuretic; its roots are used for urinary infections and its bark for fever. This study aimed to contribute to the phytochemical investigation of the toxic activity focused on the allelopathic effect of the bark of Celtis iguanaea. The ethanol extract was subjected to solvent partition with hexane, chloroform and ethyl acetate. The substances friedelin and epifriedelinol (triterpenes) were isolated from the hexane fraction and identified by spectroscopic methods ${ }^{1} \mathrm{H}$ and ${ }^{13} \mathrm{C}$ NMR. The crude extract at a concentration of $0.1 \mathrm{mg} \mathrm{mL}^{-1}$ caused marked inhibition of hypocotyl in $34.97 \%$ and stimulated radicle growth in $29.64 \%$ seedlings of Lactuca sativa. In the toxicity test against Artemia salina the crude extract and fractions showed an $\mathrm{LC}_{50}$ higher than $1000 \mu \mathrm{g} \mathrm{mL}^{-1}$, indicating that it has no toxic effect.

Key words: Allelochemicals, Celtis iguanaea, friedelin, epifriedelinol, Ulmaceae

\section{INTRODUÇÃO}

A espécie Celtis iguanaea, conhecida popularmente como esporão de galo (Silva \& Proença, 2008), pertence à família Ulmaceae (Cronquist, 1981) e possui ampla distribuição geográfica ocorrendo desde os Estados Unidos até a América do Sul (Lorenzi \& Souza, 1999). As folhas são usadas na medicina popular para o tratamento de dores no corpo, reumatismo, dores no peito, asma, cólicas, má-digestão e como diurético (Pereira et al., 2008).

Estudos etnobotânicos realizados na região do Alto Rio Grande, MG aponta o uso popular das cascas para febre (Rodrigues \& Carvalho, 2008); informações coletadas sobre folhas e raiz apresentaram um CUPs (concordância de uso popular corrigida) de $54 \%$ para uso em infecções

Recebido para publicação em 09/09/2010

Aceito para publicação em 12/03/2012

Rev. Bras. PI. Med., Botucatu, v.14, n.3, p.494-499, 2012. 
urinárias em pesquisa realizada no município de Ouro Verde de Goiás, GO (Silva \& Proença, 2008). Em cidades do Equador, as folhas e frutos (infusão) são usados para dores renais e hepáticas (Tene et al., 2007); na medicina popular do México a infusão das folhas e flores é usada para o controle do diabetes mellitus (Galicia et al., 2002).

A investigação das ações farmacológicas do extrato aquoso das folhas de Celtis iguanaea em modelos de úlcera gástrica induzida por diferentes agentes ulcerogênicos em camundongos sugerem que a espécie tem princípios ativos gastroprotetores que não reduzem a motilidade intestinal, o que pode justificar o uso popular da planta no tratamento de distúrbios gástricos (Costa et al., 2008).

A Sociedade Internacional de Alelopatia tem definido a atividade alelopática como um processo envolvendo metabólitos especiais (aleloquímicos) produzidos por plantas, microorganismos, vírus e fungos que influenciam o crescimento e desenvolvimento de sistemas agrícolas e biológicos (Alves et al., 2003).

Durante os últimos 30 anos, grande esforço tem sido dedicado à descoberta de novos aleloquímicos com potencial aplicação no manejo de plantas daninhas. Os herbicidas desenvolvidos a partir de compostos químicos naturais apresentam importantes vantagens sobre os herbicidas sintéticos usados na agricultura, pois apresentam novos mecanismos de ação, alta biodegradabilidade e baixo impacto no ambiente (Macias et al., 2006).

Atualmente, trabalhos desenvolvidos na área de alelopatia passaram a considerar a presença de agentes antioxidantes relacionados a proteínas de defesa da planta, tais como as enzimas catalase, peroxidase e superóxido dismutase, com a finalidade de elucidar os processos fisiológicos de defesa da planta (Pergo \& Ishii-Iwamoto, 2011). Entretanto, os bioensaios em laboratório com espécies comerciais ainda tem sido utilizados (Silva et al., 2009, 2010; Cândido et al., 2010), pois tem como vantagem o fato dessas espécies serem geneticamente homogêneas, apresentarem germinação uniforme e estarem facilmente disponíveis; já as espécies silvestres são geneticamente mais heterogêneas que as cultivadas e apresentam vários graus de sensibilidade para tratamento similar, além da germinação não ser uniforme (Macias et al., 2000).

Diante do exposto, o trabalho teve por objetivo avaliar a fitotoxicidade do extrato das cascas de Celtis iguanaea sobre a germinação de sementes e desenvolvimento de plântulas de Lactuca sativa $L$. e verificar se o mesmo possui toxicidade frente aos organismos vivos de Artemia salina, bem como realizar o isolamento e a identificação de substâncias químicas presentes na casca.

\section{MATERIAL E MÉTODO}

As cascas da espécie Celtis iguanaea foram coletadas no mês de outubro de 2008, no Campus Botânico da Universidade Federal do Paraná, Curitiba, Paraná, nas coordenadas geográficas de $25^{\circ} 25^{\prime} 40$ de latitude sul e 49¹6'23 de longitude oeste, a 945 metros de altitude. O material vegetal foi identificado pelo Museu Botânico Municipal de Curitiba, por comparação com uma amostra ali depositada sob o número de registro MBM 208762.

Para a obtenção do extrato bruto etanólico (EB), uma amostra das cascas secas e moídas (3000 g) foi submetida à extração por aparelho de Soxhlet e posterior concentração em evaporador rotatório com pressão reduzida à temperatura de $40^{\circ} \mathrm{C}$ e $90 \mathrm{rpm}$ até $1 / 5$ do volume. O EB foi fracionado em aparelho de Soxhlet modificado (Carvalho, 2009) com solventes em ordem crescente de polaridade, hexano, clorofórmio e acetato de etila, obtendo-se a fração hexano $(\mathrm{FH})$, fração clorofórmio (FC), fração acetato de etila (FAE) e fração hidroalcóolica remanescente (FHR). Cada uma dessas frações foi submetida à evaporação em banho-maria à temperatura de $40^{\circ} \mathrm{C}$ até obtenção do resíduo seco.

O resíduo seco da fração hexano foi dissolvido em clorofórmio, e incorporado a 2 partes de sílica-gel para cada parte de amostra, sob constante homogeneização. O solvente foi evaporado em banho-maria a $50^{\circ} \mathrm{C}$ até formação da pastilha. $A$ sílica-gel usada foi a da Merck $^{\circledR}-60$ Art. 7734 com tamanho de partícula 0,063-0,2 mm, 70-230 mesh ASTM. Essa pastilha foi submetida à cromatografia líquida em coluna de $30 \mathrm{~cm}$ de altura por $3 \mathrm{~cm}$ de diâmetro, empacotada com $30 \mathrm{~g}$ de Sílica-gel 60 $(0,063-0,200 \mathrm{~mm})$ Merck $^{\circledR}$. Na coluna foi depositado sílica-gel na proporção de 5 partes em relação a pastilha, separadas por papel de filtro. A amostra foi então eluída em sistema de solventes com gradiente de polaridade crescente. Iniciou-se com $100 \%$ de hexano $(100 \mathrm{~mL})$, tendo acetato de etila como gradiente de polaridade, com variação de 5 em 5\%, até $100 \%$ de acetato de etila. Foram coletadas 141 frações de aproximadamente $10 \mathrm{~mL}$ cada. Após evaporação do solvente foi observado cristalizações em vários frascos. Essas amostras foram submetidas à cromatografia em camada delgada (CCD) utilizandose cromatoplacas de Sílica-gel 60 F254 Merck $^{\circledR}$. Fase móvel 93:7 tolueno:acetato de etila, e a revelação com vanilina sulfúrica mostrou a presença de mistura de três compostos em todas as frações, sugerindo a presença de esteróides e/ou triterpenos. A purificação dos compostos foi feita por filtração utilizando os solventes hexano, clorofórmio e metanol, em funil sinterizado G3 a vácuo. Para a identificação, as substâncias isoladas foram submetidas às análises de espectroscopia no infravermelho e a RMN de ${ }^{1} \mathrm{H},{ }^{13} \mathrm{C}$ e DEPT $135^{\circ}$. Os espectros no infravermelho foram

Rev. Bras. PI. Med., Botucatu, v.14, n.3, p.494-499, 2012. 
obtidos com amostras preparadas em pastilhas de brometo de potássio anidro $(\mathrm{KBr})$ comprimidas em equipamento Bomem - Hartmann \& Braum MB-Serie, e os espectros de RMN ${ }^{1} \mathrm{H},{ }^{13} \mathrm{C}$ e DEPT $135^{\circ}$, do equipamento Bruker Topsin $1.3200 \mathrm{mHz}$ do Laboratório de RMN; ambos do Departamento de Química da Universidade Federal do Paraná. Após a purificação, as substâncias $\mathrm{FH}-1$ (8,7 mg) e $\mathrm{FH}-2$ (9,5 mg) foram identificadas como friedelina e epifriedelinol respectivamente (Figura 1).

$\mathrm{Na}$ avaliação da ação fitotóxica dos extratos e frações no crescimento de $L$. sativa, foram utilizadas as concentrações de 0,8, 0,4, 0,2 e 0,1 $\mathrm{mg} \mathrm{mL}^{-1}$, diluídas em $2 \mathrm{~mL}$ de etanol. A espécie alvo utilizada ( $L$. sativa) foi a cv. Babá de verão, com germinabilidade de $97 \%$.

As amostras foram embebidas em folhas de papel Whatman número $6 \mathrm{com} 1 \mathrm{~mL}$ das soluções do extrato bruto e das frações e colocadas em placa de Petri. Esse conjunto foi submetido à secagem em estufa a $50^{\circ} \mathrm{C}$ de temperatura por período de $24 \mathrm{~h}$.

Após a evaporação do solvente, os papéis de filtro correspondentes a cada diluição foram colocados em caixas Gerbox sob fluxo laminar e embebidos com $6 \mathrm{~mL}$ de água destilada e distribuídas 20 sementes em cada caixa. Após a semeadura as caixas foram envoltas com papel alumínio para a proteção da luz e colocadas em germinador Mangelsdorf, marca Biomatic ${ }^{\circledR}$, previamente regulado a temperatura de $24^{\circ} \mathrm{C}$.

No teste da germinação, durante o período de 5 dias consecutivos, foi realizada a leitura diária da germinação nas respectivas concentrações dos extratos e controles. Foram consideradas sementes germinadas aquelas que apresentavam extensão radicular igual ou superior a $2 \mathrm{~mm}$ (Lobo et al., 2008). No teste do crescimento foram separadas 10 plântulas de cada repetição e, decorridos 7 dias, foram realizadas as leituras em papel milímetrado do comprimento da radícula e do hipocótilo e comparado ao tratamento controle. $\mathrm{O}$ índice de velocidade de germinação (IVG) foi calculado através da seguinte fórmula IVG = G1/N1 + G2/N2 + G3/N3 + G4/N4 + G5/ $\mathrm{N} 5$, onde $\mathrm{G} 1, \mathrm{G} 2 \ldots \mathrm{G} 5$, Gn é o número de sementes germinadas e N1, N2... N5, Nn correspondem aos dias nos quais a germinação foi avaliada (Maguire, 1962).

Para análise estatística foi utilizado o programa SISVAR (Ferreira, 2000), e a verificação das diferenças das médias estatisticamente significativas foi realizada por meio do teste de Scott-Knott ( $5 \%$ de probabilidade).

Avaliação da toxicidade frente à Artemia salina foi realizada de acordo com a metodologia descrita por Meyer et al. (1982), com modificações, 10 larvas de Artemia salina vivas foram transferidas para tubos contendo água artificial do mar, com três diferentes concentrações dos extratos bruto e frações $\left(10,100\right.$ e $\left.1000 \mu \mathrm{g} \mathrm{mL}^{-1}\right)$, e para tubos contendo controle positivo preparado com água marinha e sulfato de quinidina. O controle negativo foi preparado com água marinha e com o solvente utilizado para diluição de cada uma das frações. Após $24 \mathrm{~h}$ foi realizada a contagem das larvas mortas e vivas. Utilizou-se esse número para o cálculo da concentração média letal $\left(\mathrm{CL}_{50}\right)$ pelo método Probit, sendo considerado sem toxicidade quando $\mathrm{CL}_{50}>1000 \mu \mathrm{g} \mathrm{mL}^{-1}$.

\section{RESULTADO}

\section{Análise Fitoquímica}

A friedelina foi isolada como sólido amorfo branco e o epifriedelinol como sólido branco na forma de cristais pontiagudos brilhantes. As substâncias foram identificadas via análise dos espectros de RMN-1H e RMN-13C (Tabela 1) e comparação com dados da literatura (Aragão et al., 1990).

As substâncias friedelina e epifriedelinol, isoladas do capim-marandu quando testadas separadamente, apresentaram baixa atividade
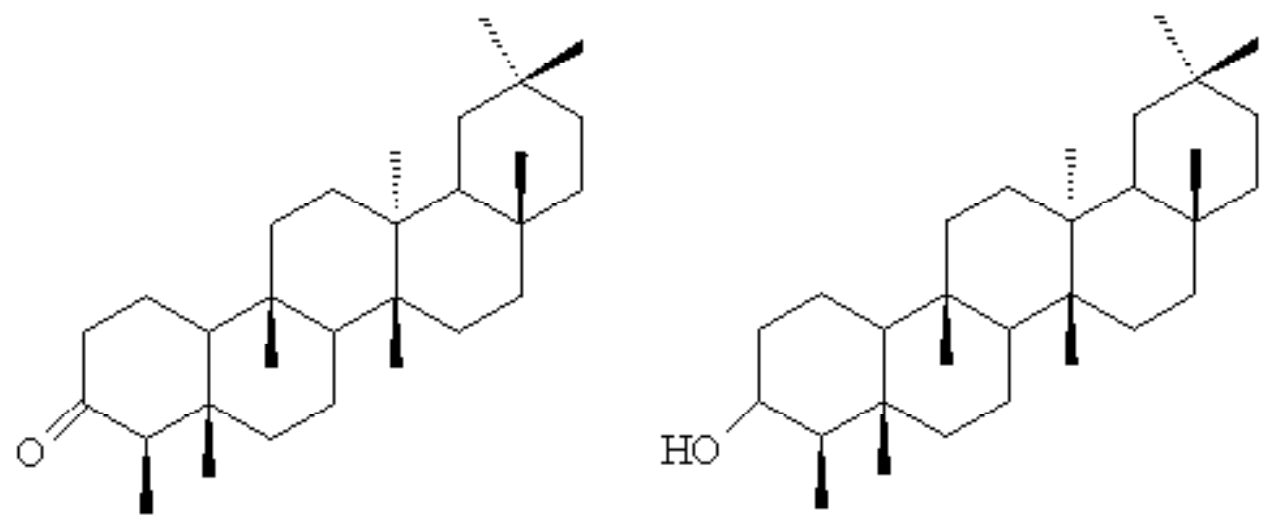

FIGURA 1. Estrutura da friedelina FH-1 e epifriedelinol FH-2. 
TABELA 1. Valores de deslocamentos químicos (d) DE RMN ${ }^{13} \mathrm{C} / \mathrm{DEPT}$ para $\mathrm{FH}-1$ e $\mathrm{FH}-2$ e dados da literatura para a friedelina e o epifriedelinol (Aragão et al., 1990).

\begin{tabular}{|c|c|c|c|c|}
\hline C & $\begin{array}{l}\text { Friedelina } \\
\text { (Literatura) }\end{array}$ & $\begin{array}{c}\text { Substância } \\
\text { FH-1 }\end{array}$ & $\begin{array}{c}\text { Epifriedelinol } \\
\text { (Literatura) }\end{array}$ & $\begin{array}{c}\text { Substância } \\
\text { FH-2 }\end{array}$ \\
\hline 1 & $22,7\left(\mathrm{CH}_{2}\right)$ & $22,3\left(\mathrm{CH}_{2}\right)$ & $15,8\left(\mathrm{CH}_{2}\right)$ & $15,8\left(\mathrm{CH}_{2}\right)$ \\
\hline 2 & $41,8\left(\mathrm{CH}_{2}\right)$ & $41,5\left(\mathrm{CH}_{2}\right)$ & $35,2\left(\mathrm{CH}_{2}\right)$ & $35,2\left(\mathrm{CH}_{2}\right)$ \\
\hline 3 & $213,0(C)$ & $213,0(C)$ & $72,7(\mathrm{C}-\mathrm{OH})$ & $72,8(\mathrm{C})$ \\
\hline 4 & $58,2(\mathrm{CH})$ & $58,2(\mathrm{CH})$ & $49,2(\mathrm{CH})$ & $49,1(\mathrm{CH})$ \\
\hline 5 & $42,8(\mathrm{CH})$ & $42,1(\mathrm{CH})$ & $41,2(\mathrm{CH})$ & $41,3(\mathrm{CH})$ \\
\hline 6 & $41,2\left(\mathrm{CH}_{2}\right)$ & $41,3\left(\mathrm{CH}_{2}\right)$ & $41,8\left(\mathrm{CH}_{2}\right)$ & $41,7\left(\mathrm{CH}_{2}\right)$ \\
\hline 7 & $18,3\left(\mathrm{CH}_{2}\right)$ & $18,6\left(\mathrm{CH}_{2}\right)$ & $17,6\left(\mathrm{CH}_{2}\right)$ & $17,5\left(\mathrm{CH}_{2}\right)$ \\
\hline 8 & $53,2(\mathrm{CH})$ & $53,1(\mathrm{CH})$ & $53,2(\mathrm{CH})$ & $53,2(\mathrm{CH})$ \\
\hline 9 & $37,8(C)$ & $37,4(\mathrm{C})$ & $37,8(\mathrm{C})$ & $37,1(\mathrm{C})$ \\
\hline 10 & $59,5(\mathrm{CH})$ & $59,5(\mathrm{CH})$ & $61,4(\mathrm{CH})$ & $61,3(\mathrm{CH})$ \\
\hline 11 & $35,2\left(\mathrm{CH}_{2}\right)$ & $35,0\left(\mathrm{CH}_{2}\right)$ & $35,6\left(\mathrm{CH}_{2}\right)$ & $35,5\left(\mathrm{CH}_{2}\right)$ \\
\hline 12 & $32,4\left(\mathrm{CH}_{2}\right)$ & $32,4\left(\mathrm{CH}_{2}\right)$ & $32,9\left(\mathrm{CH}_{2}\right)$ & $32,8\left(\mathrm{CH}_{2}\right)$ \\
\hline 13 & $38,2(C)$ & $38,3(\mathrm{C})$ & $38,2(C)$ & $38,3(\mathrm{C})$ \\
\hline 14 & $39,7(\mathrm{C})$ & $39,2(\mathrm{C})$ & $39,7(C)$ & $39,7(C)$ \\
\hline 15 & $30,6\left(\mathrm{CH}_{2}\right)$ & $30,5\left(\mathrm{CH}_{2}\right)$ & $30,6\left(\mathrm{CH}_{2}\right)$ & $30,6\left(\mathrm{CH}_{2}\right)$ \\
\hline 16 & $36,1\left(\mathrm{CH}_{2}\right)$ & $36,0\left(\mathrm{CH}_{2}\right)$ & $36,1\left(\mathrm{CH}_{2}\right)$ & $36,1\left(\mathrm{CH}_{2}\right)$ \\
\hline 17 & $30,0(\mathrm{C})$ & $29,7(C)$ & $29,3(\mathrm{C})$ & 29,7 (C) \\
\hline 18 & $42,9(\mathrm{CH})$ & $42,8(\mathrm{CH})$ & $42,9(\mathrm{CH})$ & $42,8(\mathrm{CH})$ \\
\hline 19 & $35,3\left(\mathrm{CH}_{2}\right)$ & $35,6\left(\mathrm{CH}_{2}\right)$ & $35,6\left(\mathrm{CH}_{2}\right)$ & $35,3\left(\mathrm{CH}_{2}\right)$ \\
\hline 20 & $28,2(\mathrm{C})$ & $28,2(\mathrm{C})$ & $28,2(\mathrm{C})$ & 28,2 (C) \\
\hline 21 & $32,9\left(\mathrm{CH}_{2}\right)$ & $32,8\left(\mathrm{CH}_{2}\right)$ & $32,9\left(\mathrm{CH}_{2}\right)$ & $32,3\left(\mathrm{CH}_{2}\right)$ \\
\hline 22 & $39,3\left(\mathrm{CH}_{2}\right)$ & $39,2\left(\mathrm{CH}_{2}\right)$ & $39,3\left(\mathrm{CH}_{2}\right)$ & $39,3\left(\mathrm{CH}_{2}\right)$ \\
\hline 23 & $6,8\left(\mathrm{CH}_{3}\right)$ & $6,8\left(\mathrm{CH}_{3}\right)$ & $11,6\left(\mathrm{CH}_{3}\right)$ & $11,6\left(\mathrm{CH}_{3}\right)$ \\
\hline 24 & $14,1\left(\mathrm{CH}_{3}\right)$ & $14,6\left(\mathrm{CH}_{3}\right)$ & $16,4\left(\mathrm{CH}_{3}\right)$ & $16,4\left(\mathrm{CH}_{3}\right)$ \\
\hline 25 & $18,2\left(\mathrm{CH}_{3}\right)$ & $17,9\left(\mathrm{CH}_{3}\right)$ & $18,2\left(\mathrm{CH}_{3}\right)$ & $18,2\left(\mathrm{CH}_{3}\right)$ \\
\hline 26 & $18,6\left(\mathrm{CH}_{3}\right)$ & $18,3\left(\mathrm{CH}_{3}\right)$ & $18,6\left(\mathrm{CH}_{3}\right)$ & $18,6\left(\mathrm{CH}_{3}\right)$ \\
\hline 27 & $20,1\left(\mathrm{CH}_{3}\right)$ & $20,2\left(\mathrm{CH}_{3}\right)$ & $20,1\left(\mathrm{CH}_{3}\right)$ & $20,1\left(\mathrm{CH}_{3}\right)$ \\
\hline 28 & $32,1\left(\mathrm{CH}_{3}\right)$ & $32,1\left(\mathrm{CH}_{3}\right)$ & $32,1\left(\mathrm{CH}_{3}\right)$ & $32,1\left(\mathrm{CH}_{3}\right)$ \\
\hline 29 & $31,8\left(\mathrm{CH}_{3}\right)$ & $31,8\left(\mathrm{CH}_{3}\right)$ & $31,8\left(\mathrm{CH}_{3}\right)$ & $31,8\left(\mathrm{CH}_{3}\right)$ \\
\hline 30 & $35,0\left(\mathrm{CH}_{3}\right)$ & $35,3\left(\mathrm{CH}_{3}\right)$ & $35,0\left(\mathrm{CH}_{3}\right)$ & $35,0\left(\mathrm{CH}_{3}\right)$ \\
\hline
\end{tabular}

inibitória da germinação de sementes e do desenvolvimento da radícula e do hipocótilo das plantas daninhas malícia (Mimosa pudica) e matapasto (Senna obtusifolia). Quando utilizadas conjuntamente, os efeitos inibitórios foram ligeiramente superiores àqueles obtidos pelas substâncias isoladamente, indicando a ocorrência de efeito aditivo (Santos et al., 2008).

\section{Avaliação fitotóxica do extrato bruto etanólico}

A Tabela 2 demonstra os resultados obtidos na avaliação da influência do extrato bruto etanólico nas concentrações 0,$1 ; 0,2 ; 04$ e $0,8 \mathrm{mg} \mathrm{mL}^{-1}$, sobre o crescimento da raiz primária e do hipocótilo das sementes da espécie Lactuca sativa e dos Índices de Velocidade de Germinação (IVG). Apenas a concentração de $0,1 \mathrm{mg} \mathrm{mL}^{-1}$ foi estatisticamente diferente do controle, e, de acordo com os resultados apresentados, houve estimulo do crescimento da raiz primária quando comparada ao controle água em $29,64 \%$, e inibição de $34,97 \%$ do crescimento dos hipocótilos. As demais concentrações das frações hexano, clorofórmio, acetato de etila e remanescente, não apresentaram alteração estatisticamente significativa quando comparadas ao controle. O resultado do teste de Scott-Knott realizado sobre os Índices de Velocidade de Germinação (IVG) frente ao extrato bruto e frações quando comparados ao controle testado, demonstram ser estatisticamente iguais, não apresentando, portanto, influência estatisticamente significativa.

\section{Avaliação da toxicidade das cascas de Celtis iguanaea frente à Artemia salina}

Em relação aos resultados obtidos para a toxicidade frente $A$. salina, foi verificado que os mesmo não interferem nas condições avaliadas, uma vez que apresentaram valores de CL50>1000 ppm, ou seja, não apresenta toxicidade, para esse ensaio (Tabela 3).

TABELA 2. Efeito das concentrações do extrato etanólico bruto de Celtis iguanaea no crescimento da raiz primária e hipocótilo e no Índice de Velocidade de Germinação (IVG) de L. sativa.

\begin{tabular}{cccc}
\hline $\begin{array}{c}\text { Concentraçãomg } \\
\mathbf{m L}^{-1}\end{array}$ & $\begin{array}{c}\text { Tamanho do hipocótilo em } \mathbf{c m} \\
\text { (média de 4 repetições) }\end{array}$ & $\begin{array}{c}\text { Tamanho da radícula em cm } \\
\text { (média de 4 repetições) }\end{array}$ & $\begin{array}{c}\text { Índice de Velocidade } \\
\text { de Germinação (IVG) }\end{array}$ \\
\hline 0,1 & $2,36 \mathrm{~b}$ & $4,96 \mathrm{~b}$ & $4,40 \mathrm{a}$ \\
0,2 & $3,72 \mathrm{a}$ & $4,060 \mathrm{a}$ & $4,63 \mathrm{a}$ \\
0,4 & $3,79 \mathrm{a}$ & $3,69 \mathrm{a}$ & $4,88 \mathrm{a}$ \\
0,8 & $3,62 \mathrm{a}$ & $3,77 \mathrm{a}$ & $4,58 \mathrm{a}$ \\
Controle (Água) & $3,735 \mathrm{a}$ & $4,026 \mathrm{a}$ & $4,87 \mathrm{a}$ \\
\hline
\end{tabular}

NOTA: (1) Médias seguidas de mesma letra do controle não diferem entre si pelo teste de Scott- Knott a $5 \%$ de probabilidade. 
TABELA 3. $\mathrm{CL}_{50}$ e mortalidade de $A$. salina, submetidas ao extrato etanólico bruto e frações semipurificadas de Celtis iguanaea.

\begin{tabular}{lccc}
\hline Amostra & $\begin{array}{c}\text { Concentração } \\
\left(\mu \mathbf{g ~ m L}^{1-}\right)\end{array}$ & $\begin{array}{c}\mathbf{C L}_{50} \\
\left(\mu \mathbf{g ~ m L}^{1-}\right)\end{array}$ & $\begin{array}{c}\text { Intervalo de confiança } \\
\mathbf{d e ~} 95 \%\left(\mu \mathbf{~ m L}^{-1}\right)\end{array}$ \\
\hline Extrato Bruto & 10 & $>1000$ & \\
\hline Fração Hexano & 100 & $>1000$ \\
& 1000 & \\
\hline Fração Clorofórmio & 100 & $>1000$ \\
& 1000 & \\
\hline Fração Acetato de Etila & 10 & $>1000$ \\
& 100 & \\
\hline Fração Remanescente & 100 & $>1000$ \\
\hline Sulfato de quinidina & 1000 & \\
& 10 & \\
& 100 & 50,12 \\
\hline
\end{tabular}

\section{DISCUSSÃO}

O estudo químico da fração hexano permitiu o isolamento e a identificação dos triterpenos pentacíclicos da série friedelano, a friedelina e o epifriedelinol, este último já isolado anteriormente da casca de Celtis sinensis (Kim et al., 2005). Triterpenos já foram identificados como aleloquímicos em outras plantas. Esses compostos podem ser responsáveis, de modo isolado ou sinergístico, pela interferência nos processos fisiológicos durante a fase de crescimento de monocotiledôneas e eudicotiledôneas (Einhellig, 2002). As alterações no padrão de germinação e crescimento podem ser resultantes de diversos efeitos causados em nível primário (Gusman et al., 2008). Dentre eles, Ferreira \& Áquila (2000) destacam as alterações na permeabilidade de membranas, na transcrição e tradução do DNA, no funcionamento de mensageiros secundários, na respiração pelo sequestro do oxigênio, na conformação de enzimas e receptores, ou ainda, pela combinação destes fatores.

No bioensaio de crescimento, apenas o extrato bruto etanólico na maior concentração ensaiada apresentou influencia acentuada no crescimento do hipocótilo e raiz primária de Lactuca sativa, demonstrando o potencial efeito fitotoxico que poderá, com pesquisas futuras como ensaios de campo e avaliação de atividades enzimáticas, resultar em ação alelopática. Com relação aos resultados de toxicidade obtidos frente $A$. salina, resultados similares foram obtidos por Pereira et al. (2008) que, ao investigarem o potencial mutagênico e recombinogênico do extrato aquoso das folhas de Celtis iguanaea em células somáticas de Drosophila melanogaster, não verificaram efeito mutagênico e recombinogênio sobre as células analisadas. Os dados aqui obtidos mostram a relevância no estudo dos compostos químicos isolados presentes no extrato bruto com atividade fitotóxica em $L$. sativa, pois a ausência de toxicidade apresentada frente $A$. salina infere que estes não são tóxicos a organismos vivos e, consequentemente, ao meio ambiente. $A$ Artemia sp é utilizada desde a década de 50 para inúmeros estudos de ecotoxicidade e na avaliação de produtos como pesticidas, derivados do petroquímicos e dispersantes, metais pesados, derivados carcinogênicos além de metabólitos de microorganismos. Como os produtos naturais estão sujeitos aos mesmos problemas tóxicos dos pesticidas, pesquisas alelopáticas e de fitotoxicidade devem ser conduzidas paralelamente a estudos de ecotoxicidade e toxicidade para humanos, uma vez que substâncias desenvolvidas e utilizadas como agrotóxicos podem causam danos ambientais e a saúde humana (Lima et al., 2011). 
Estudos com a espécie Celtis iguanaea devem ser realizados em campo sobre o efeito em espécies daninhas e com a finalidade de estabelecer a ação fitotóxica destes compostos no ambiente.

\section{AGRADECIMENTO}

Ao Programa de Pós Graduação em Ciências Farmacêuticas da Universidade Federal do Paraná e ao Museu Botânico da Prefeitura Municipal de Curitiba.

\section{REFERÊNCIA}

ALVES, C.C.F. et al. Atividade alelopática de alcalóides glicosilados de Solanum crinitum Lam. Floresta e Ambiente, v.10, n.1, p.93-7, 2003.

ARAGÃO, P.C.A. et al. Substâncias isoladas de Stigmaphyllon tomentosum e Byrsonima Variabilis. Química Nova, v.13, n.4, p.254-9, 1990.

CÂNDIDO, A.C.S. et al. Allelopathy potencial of Senna occidentalis (L.). Allelopathy Journal, v.26, n.1, p.35-44, 2010.

CARVALHO, J.L.S. et al. Termoestabilidade de processos extrativos de Nasturtium officinale R. Br., Brassicaceae por sistema Soxhlet modificado. Química Nova, v.32, n.4, p.1031-5, 2009.

COSTA, E.A. et al. Efeito gastroprotetor do extrato aquoso de Celtis iguanaea (Jacq.) Sargent (esporão de galo). Disponível em: <http://www.fesbe.org.br/ regional2008/?resumos/36.019>. Acesso em: 01 nov. 2008.

CRONQUIST, A. An integrated system of classification of flowering plants. New York: Columbia University Press, 1981. p.191-2.

EINHELLIG, F.A. The physiology of allelochemical action: clues and views. In: REIGOSA, M.; PEDROL, N. Allelopathy from molecules to ecosystems. Vigo: Universidade de Vigo, 2002. p.1-23.

FERREIRA, A.G.; AQUILA, M.E. Alelopatia: uma área emergente da ecofisiologia. Revista Brasileira de Fisiologia Vegetal, v.12, p.175-204, 2000.

FERREIRA, D.F. Sistema de análise de variância de dados balanceados (SISVAR). Pacote computacional. Lavras: UFLA, 2000. 66p.

GALICIA, E.H. et al. Studies on hypoglycemic activity of Mexican medicinal plants. Western Pharmacology Society, v.45, p.118-24, 2002.

GUSMAN, G.S. et al. Alelopatia de Baccharis dracunculifolia DC. sobre a germinação e desenvolvimento de espécies cultivadas. Acta Scientiarum Biological Sciences, v.30, p.119-25, 2008.

$\mathrm{KIM}$, D.K. et al. Antitumor and antiinflammatory constituents from Celtis sinensis. Archives of Pharmacal Research, v.28, n.1, p.39-43, 2005.

LIMA, C.P. et al. Efeito alelopático e toxicidade frente à Artemia salina Leach dos extratos do fruto de Euterpe edulis Martius. Acta Botanica Brasílica, v.25, n.2, p.3316, 2011.

LOBO, L.T. et al. Potencial alelopático de catequinas de Tachigali myrmecophyla (LEGUMINOSAE). Química Nova, v.31, n.3, p.493-7, 2008.

LORENZI, H.; SOUZA, H.M. Plantas ornamentais do Brasil. 2.ed. Nova Odessa: Instituto Plantarum, 1999. 869p.

MACIAS, F.A. et al. Sesquiterpene lactones with potencial use as natural herbicides models. Journal of Agricultural and Food Chemistry, v.48, p.5288-96, 2000. MACIAS, F.A. et al. Sesquiterpene lactones as allelochemicals. Journal Natural Products, v.69, p.795800, 2006.

MAGUIRE, J.D. Speed of germination-aid in selection evaluation for seedling emergence and vigour. Crop Science, v.2, p.176-7, 1962.

MEYER, B.N. et al. Brine Shrimp: a convenient general bioassay for active plant constituents. Planta Medica, v.45, p.31-4, 1982.

PEREIRA, K.C.S. et al. Ausência de efeito genotóxico do extrato de esporão-de-galo em células somáticas de Drosophila melanogaster. In: CONGRESSO BRASILEIRO DE GENÉTICA, 54., 2008, Salvador. Livro de Resumos... Salvador: SBG, 2008. p.111.

PERGO, E.M.; ISHII-IWAMOTO, E.L. Changes in energy metabolism and antioxidant defense systems during seed germination of the weed species Ipomoea triloba $\mathrm{L}$. and the responses to allelochemicals. Journal of Chemical Ecology, v.37, p.500-14, 2011.

RODRIGUES, V.E.; CARVALHO, D.A. Florística de plantas medicinais nativas de remanescentes de floresta estacional semidecidual na região do Alto do Rio Grande, Minas Gerais. Revista Cerne, v.14, n.2, p.93-112, 2008. SANTOS, L.S. et al. Atividade alelopática de substâncias químicas isoladas do Campim-Marandu e suas variações em função do pH. Planta Daninha, v.26, n.3, p.531-8, 2008.

SILVA, C.S.P.; PROENÇA, C.E.B. Uso e disponibilidade de recursos medicinais no município de Ouro Verde de Goiás, GO, Brasil. Acta Botanica Brasílica, v.22, n.2, p.481-92, 2008.

SILVA, C.B. et al. Composição química e atividade alelopática do óleo volátil de Hydrocotyle bonariensis Lam. (Araliaceae). Quimica Nova, v.32, p.2373-6, 2009. SILVA, C.B. et al. Atividade alelopática, antioxidante e teor de fenóis totais de Hydrocotyle bonariensis Lam. (Araliaceae). Acta Scientiarum Technology, v.32, p.41320, 2010.

TENE, V. et al. An ethnobotanical survey of medicinal plants used in Loja and Zamora-Chinchipe, Ecuador. Journal of Ethnopharmacology, v.111, p.63-81, 2007. 